\title{
AVALIAÇÃO DE SELEÇÕES MUTANTES DE FIGUEIRA cv. ROXO-DE-VALINHOS ${ }^{1}$
}

\author{
MARIA GABRIELA FONTANETTI RODRIGUES², LUIZ DE SOUZA CORREA, \\ APARECIDA CONCEIÇÃO BOLIANI ${ }^{3}$
}

RESUMO - A figueira (Ficus carica L.), pertencente à família das Moráceas, constitui-se numa das mais importantes frutíferas cultivadas, elevando o Brasil à condição de décimo maior produtor e exportador de figos do mundo. Porém, a ficicultura apresenta alguns problemas fitossanitários, além de, no Brasil, estar toda implantada com uma única cultivar, a Roxo-de-Valinhos, que produz frutos sem sementes, inviabilizando o melhoramento convencional. Nesse sentido, o melhoramento genético, com o uso de mutagênicos, passa a ser uma linha de pesquisa altamente importante, podendo contribuir enormemente para o desenvolvimento da cultura. Diante disto, o objetivo do presente trabalho foi avaliar seleções mutantes de figueira originadas de plantas formadas por estacas provenientes de gemas irradiadas com raio gama, bem como compará-las com as principais cultivares da cultura em plantio comercial. Utilizou-se de plantas originadas de estacas de 5 cultivares tradicionais de figueira e de cinco seleções de figueiras mutantes (formadas por estacas originadas de gemas da cultivar Roxo-de-Valinhos irradiadas com raio gama, na dose de $30 \mathrm{~Gy}$ ), cultivadas em espaçamento de 2,5 x 1,5 m. O delineamento experimental utilizado foi o de blocos inteiramente casualizados, contendo 10 tratamentos, com 3 repetições e 5 plantas por parcela. As avaliações foram realizadas a partir do desenvolvimento vegetativo das plantas, bem como as características dos frutos. Da análise dos dados, conclui-se que há variabilidade entre as seleções mutantes e destas com as cultivares tradicionais, e que o tratamento PI-189 foi superior à cultivar-padrão Roxo-de-Valinhos em características de grande importância comercial, como "número de frutos por planta", "massa média por fruto" e "produtividade", igualando-se nas demais características, mostrando-se, assim, com enorme potencial para posteriores estudos.

Termos para Indexação: Ficus carica, radiação gama, mutação.

\section{EVALUATION OF FIGS MUTANT SELECTIONS cv. ROXO-DE-VALINHOS}

\begin{abstract}
The fig (Ficus carica L.), belonging to the Moraceas family, is one of the most important fruit crops, bringing Brazil to the condition of the tenth largest fig producer and exporter in the world. But the culture presents some problems with plant protection, and in Brazil, it is all implanted with an only cultivar, Roxo-de-Valinhos, which produces seedless fruit, not permitting the conventional improvement. In this sense, the genetic improvement by using mutagenic becomes a very important research line, that can greatly contribute to the culture development. Considering this, this study aimed to evaluate selections of fig originated from mutant plants formed by cuttings from buds irradiated with gamma ray and compare them with the main varieties of the culture in commercial plantation. By using plants originated from 5 traditional fig cultivars cuttings and 5 fig mutant selections (formed by cuttings from Roxo-de-Valinhos buds irradiated with gamma ray, in the dose of $30 \mathrm{~Gy}$ ), spaced by $2.5 \times 1.5 \mathrm{~m}$. The experimental layout was a completely randomized block design, with 10 treatments, 3 repetitions and 5 plants per plot. The evaluations are made from the plants vegetative growth as well as the fruit characteristics. Through data analysis, it seems that there is variability between the mutant selections and with the traditional cultivars, and the treatment PI-189 was superior to the standard cultivar Roxo-de-Valinhos on great commercial characteristics importance, such as "number of fruit per plant", "average weight per fruit" and "productivity", having the same traits, showing itself with enormous potential for future studies.
\end{abstract}

Index terms: Ficus carica, gamma radiation, mutation.

\footnotetext{
${ }^{1}$ (Trabalho 215-08). Recebido em: 15-08-2008. Aceito para publicação em: 16-02-2009.

${ }^{2}$ Eng. Agrônoma. Bolsista FAPESP - Universidade Estadual Paulista (UNESP), Ilha Solteira-SP; gabrielafontanetti@hotmail.com ${ }^{3}$ Docentes do Depto. Fitotecnia, Tecnologia de Alimentos e Sócio-Economia da FEIS-UNESP, 1correa@agr.feis.unesp.br; boliani@agr.feis.unesp.br
} 


\section{INTRODUÇÃO}

A figueira (Ficus carica L.) é uma frutífera pertencente à família das Moráceas que se adapta a uma ampla diversidade climática, sendo cultivada tanto em regiões subtropicais quentes, como, principalmente, em clima temperado (Pereira, 1981).

O figo está entre as vinte principais frutas exportadas pelo Brasil e vem mantendo a terceira posição no ranking de volume comercializado, entre as frutas de clima temperado, com uma produção de 900 toneladas anuais. O Brasil ocupa a $10^{\mathrm{a}}$ colocação em termos de produção mundial, sendo responsável por $2 \%$ da mesma (IEA, 2008).

Os principais Estados produtores de figo no Brasil são: Rio Grande do Sul com produção destinada à indústria, São Paulo com a produção de frutos para mesa e Minas Gerais com frutos para mesa e indústria (Penteado, 1999).

Além de sua expressão econômica e participação na complementação da dieta alimentar, a ficicultura é caracterizada como atividade de pequenas áreas, contribuindo para a sobrevivência da propriedade agrícola familiar.

A cultura apresenta problemas relativos a pragas e doenças, que interferem negativamente no seu cultivo, reduzindo os lucros, dos quais se podem destacar: nematoides, ferrugem (Cerotelium fici Cast.), seca-da-figueira (Botrydiplodia sp.), brocada-figueira (Azochis gripusalis Walk.) e moscado-figo (Zaprionus indianus Gupta.). A cultivar 'Roxo-de-Valinhos'é muito suscetível ao nematóide Meloidogyne incognita, que ataca as raízes da planta, formando galhas, prejudicando assim seu desenvolvimento e exigindo altos gastos com insumos e tratos culturais (Ferraz et al. 1980).

No Estado de São Paulo, principal produtor brasileiro, existem cerca de 25 cultivares de figueira, das quais a única cultivada comercialmente é a 'Roxo-de-Valinhos' (Pereira \& Nachtigal, 1999). Essa cultivar é caracterizada pelo seu elevado vigor e produtividade, porém sua propagação dá-se exclusivamente por via assexuada (Correa \& Boliani, 1999). Sabe-se que as plantas de propagação vegetativa, como normalmente ocorre com o Ficus carica, apresentam algumas dificuldades para a aplicação dos métodos clássicos de melhoramento (Donini, 1976).

No caso da figueira, tem-se apenas o caprifigo como planta que apresenta flores masculinas; aliado a isso, pouco se conhece da figueira sobre sua base genética relativa às características a serem melhoradas. Assim, pode-se dificultar a realização de cruzamentos e posteriores seleções e recuperação de um genótipo que associe as características básicas da cultivar original e as que se pretendia introduzir. Possivelmente por estas razões, é que mutações somáticas espontâneas em muitas frutíferas têm contribuído para a obtenção de cultivares de grande importância econômica, como, por exemplo, no caso de citros no Brasil (Domingues et al., 1995). O melhoramento da figueira apresenta algumas destas dificuldades citadas e por isso outras técnicas, tais como indução de mutação, podem ser sugeridas, já que os mutagênicos podem aumentar em milhares de vezes a frequência de mutações espontâneas.

Existem várias razões que tornam a figueira uma cultura atrativa para o uso de indução de mutação. Apesar disso, existem poucos trabalhos em que esta alternativa tem sido utilizada (Tulmann Neto et al., 1999).

De acordo com a literatura, o uso de técnicas de indução de mutação tem trazido resultados de interesse em frutíferas. Em videira, folhas foram irradiadas com raio gama in vitro, obtendo-se tetraploides nas plantas regeneradas e aumento na variabilidade genética (Kuksova et al., 1997). Em pera, por meio da irradiação com raios gama e micropropagação in vitro e posterior avaliação no campo, foram selecionados mutantes de porte compacto em frequências que variaram de 0,5 a $2,7 \%$, de acordo com a variedade (Predieri et al., 1997).

Kerkadze (1987) obteve um mutante de figueira (variedade Bolinzhir) através de irradiação gama, mostrando a viabilidade da técnica.

Diante do exposto, o objetivo do presente trabalho foi avaliar seleções mutantes de figueira (Ficus carica L.) originadas de plantas formadas por estacas provenientes de gemas irradiadas com raio gama, bem como compará-las com as principais cultivares da cultura em plantio comercial.

\section{MATERIAL E MÉTODOS}

O experimento foi conduzido na Fazenda de Ensino, Pesquisa e Extensão da UNESP - Campus de Ilha Solteira, localizada no município de SelvíriaMS, que apresenta clima tipicamente de cerrado.

Quanto aos tratos culturais, as adubações foram realizadas de acordo com análise de solo e recomendações de Raij et al. (1997), na projeção da copa das figueiras, com o terreno desprovido de cobertura morta. Após a aplicação, colocou-se novamente a cobertura morta (bagaço de cana), com o intuito de proteger o solo contra erosão, manter a umidade e controlar plantas daninhas.

O tratamento fitossanitário constou de apli- 
cações quinzenais de Calda Bordalesa (1\%), bem como Mancozeb (200 g p.c./100 litros de água), visando-se a controlar especialmente a ferrugem-dafigueira (Cerotelium fici Cast.) e Methyl Parathion (100 mL/100 litros de água) visando ao controle da broca-da-figueira (Azochis gripusalis Walk.), aplicado juntamente com a Calda Bordalesa. Para o controle de nematoides, plantou-se, nas entre-linhas, a Crotalaria spectabiles. A irrigação foi feita com uso de uma fita gotejadora, 3 vezes por semana, com uma precipitação média de $2,0 \mathrm{~mm} / \mathrm{h}$, atingindo uma faixa de $50 \mathrm{~cm}$ de largura na linha de plantio.

O experimento foi instalado no mês de agosto de 2007, utilizando-se de plantas originadas de estacas de 5 cultivares tradicionais de figueira e de cinco seleções de figueiras mutantes, obtidas em experimento prévio, que constou da avaliação de 450 plantas de figueira formadas por estacas originadas de gemas da cultivar Roxo-de-Valinhos irradiadas com raio gama, na dose de $30 \mathrm{~Gy}$, como descrito por Santos et al. (1997), no Centro de Energia Nuclear na Agricultura (CENA/USP) em Piracicaba, no ano de 1998, no qual foram caracterizados: número de lobos por folha; comprimento e largura do limbo foliar; comprimento do pecíolo das folhas; formato dos frutos, bem como seu comprimento e diâmetro; comprimento do pedúnculo; tamanho e abertura do ostíolo; coloração da polpa; e incidência de ferrugem, broca-da-figueira e nematoide.

O delineamento experimental utilizado foi o de blocos inteiramente casualizados, contendo 10 tratamentos, com 3 repetições e 5 plantas por parcela, no espaçamento $2,5 \times 1,5 \mathrm{~m}$.

Os tratamentos encontram-se descritos a seguir:

01- Cultivar Roxo de Valinhos

02- Cultivar Pingo de Mel

03- Cultivar White Genova

04- Cultivar White Adriatic

05- Cultivar Palestino

06- Seleção Planta Irradiada - 440 (PI - 440): fruto alongado

07- Seleção Planta Irradiada - 433 (PI - 433): pedúnculo longo

08- Seleção Planta Irradiada -189 (PI - 189):

ostíolo fechado e pequeno

09- Seleção Planta Irradiada - 214 (PI - 214): fruto grande

10- Seleção Planta Irradiada -301 (PI - 301): fruto alongado e grande

No período de desenvolvimento das plantas, foram avaliados: altura $(\mathrm{cm})$ das plantas a cada 10 dias, utilizando-se de fita métrica, medindo-se desde o colo da planta até sua gema apical; taxa de cresci- mento relativo (TCR, em $\mathrm{cm} / \mathrm{cm}$.dia), que consiste no incremento da matéria seca total, por unidade de matéria seca total existente, por unidade de tempo; e número de nós no ramo principal, no início da frutificação, através da contagem do número de nós a partir do colo da planta até o nó que continha o primeiro fruto.

Quanto às características avaliadas nos frutos, duas vezes por semana, de janeiro a março de 2008, todos os frutos em estado de maturação foram colhidos e, em cada planta, foram avaliados: número de frutos por planta; massa média dos frutos (g); produtividade, em kg por área cultivada, convertida em toneladas por hectare; comprimento $(\mathrm{cm})$ e diâmetro $(\mathrm{cm})$ de cada fruto, com auxílio de um paquímetro; sólidos solúveis, expresso em ${ }^{\circ} \mathrm{Brix}$, com auxílio de um refratômetro e corrigido de acordo com a tabela de correção da leitura do Brix refratométrico para a temperatura-padrão de $20{ }^{\circ} \mathrm{C}$; e acidez titulável, determinada por titulometria de neutralização, por titulação de $20 \mathrm{~g}$ de polpa, homogeneizada e diluída para $500 \mathrm{ml}$ em água destilada, com solução padronizada de hidróxido de sódio a $0,05 \mathrm{~N}$, expressa em $\%$ de ácido cítrico.

A partir dos resultados obtidos, efetuou-se a análise estatística em todos os tratamentos, nas diferentes época de avaliação. As médias obtidas foram comparadas pelo teste de Tukey, a 5\% de probabilidade. Para a execução das análises estatísticas, foram utilizados o programa Statistical Analysis Software e planejamento de experimentos - SISVAR.

\section{RESULTADOS E DISCUSSÃO}

De modo geral, desde a primeira avaliação, os diversos tratamentos mantiveram o mesmo comportamento em termos de altura das plantas. Aos 130 dias após o plantio no campo, constata-se que as plantas de menor porte foram as da PI - 433, o que pode ser de caráter genético devido à mutação ou a um possível enfezamento das plantas que, segundo Ribeiro (1999), caracteriza-se por apresentar como sintoma principal o nanismo, muito comum em figueiras. Os resultados da taxa de crescimento relativo, para os diferentes tratamentos e intervalos, mostram semelhanças entre os tratamentos, ao longo do ciclo das plantas de figueira. A redução na TCR entre 70 e 80 dias após a semeadura, provavelmente, é devido ao início de frutificação e desenvolvimento dos frutos neste período, podendo ser observado na Figura 1.

Chiariello et al. (1991) acrescentam que a taxa de crescimento relativo é a variável fundamental da 
análise de crescimento tradicional, porque fornece o índice fisiológico mais proveitoso e ecologicamente significante. Nesse contexto, a TCR pode refletir de modo claro o efeito do estresse hídrico no acúmulo de matéria seca total, como verificado por Stone et al. (1988) e Moreira (1993), em Phaseolus.

Na Tabela 1, encontram-se os dados referentes ao número de nós da inserção do ramo até a inserção do primeiro fruto no mesmo. A análise revela que houve diferença estatística significativa entre os tratamentos. A PI - 433 foi a que apresentou menor número de nós até o primeiro fruto, ou seja, a que apresentou frutificação mais baixa (no sétimo nó), porém não diferiu estatisticamente dos tratamentos 'Roxo-de-Valinhos', 'Pingo-de-Mel', 'Palestino', PI-189 e PI-214. A frutificação da figueira, quanto mais baixa em termos do ramo formado, é uma característica desejável, pois poderá dar maiores produções por ramo; tal característica também pode ser alcançada através da prática de poda (Correa \& Santos, 1999).

Com relação aos frutos, observa-se que houve diferença significativa entre os tratamentos em praticamente todas as características avaliadas, como pode ser observado na Tabela 2.

Analisando-se o número de frutos por planta, verifica-se que as cultivares Palestino e a PI - 189 apresentaram maior número de frutos em relação às outras cultivares, apesar de não diferirem estatisticamente da cultivar Pingo-de-Mel; e que as cultivares White Genova e a PI - 440 apresentaram a menor quantidade de frutos, em número absoluto, quando comparados com os demais tratamentos. A cultivar White Adriatic não produziu frutos, impossibilitando a avaliação dos mesmos.

A massa média dos frutos variou entre 19,27g e $51,33 \mathrm{~g}$, sendo o tratamento de destaque a cultivar White Genova, juntamente com PI-189, PI-214 e PI-301, havendo diferença significativa quando comparados aos demais tratamentos. Verifica-se que as produtividades dos tratamentos obtiveram diferença significativa entre si, variando entre $0,99 \mathrm{t} / \mathrm{ha}$ e $3,76 \mathrm{t}$ / ha, sendo estes valores referentes, respectivamente, aos tratamentos PI - 440 e PI - 189.

Conforme dados do Ministério da Agricultura (2005), a área colhida com a cultura da figueira no Brasil, em 2003, foi de 3.130 ha, com produção de 25.586 toneladas, alcançando produtividade média de $8,2 \mathrm{t} / \mathrm{ha}$, chegando a $25 \mathrm{t} / \mathrm{ha}$ em algumas regiões. As produtividades aqui obtidas foram menores que a média obtida pelo Ministério da Agricultura, uma vez que a produção deste trabalho foi avaliada do quinto ao sétimo mês após a instalação do experimento.

Os tratamentos não diferiram significativamente entre si em relação ao comprimento dos frutos, com exceção da cultivar Pingo-de-Mel, que apresentou o menor valor. Já para diâmetro, as cultivares 'White Genova' e 'Roxo-de-Valinhos', e PI - 189, PI - 214 e PI - 301 destacaram-se dos demais tratamentos.

Ao analisar os sólidos solúveis, pode-se observar pouca variação entre os tratamentos e valores compatíveis com o observado por Turk (1989), que caracteriza o figo brasileiro como tendo sólidos solúveis por volta de $11,08^{\circ} \mathrm{Brix}$.

Com relação à acidez titulável, observa-se que a cultivar Pingo-de-Mel obteve destaque em relação às demais, uma vez que os valores foram baixos e com pequenas variações entre tratamentos $(0,13$ a $0,18 \%)$; os quais se encontram dentro da normalidade de acordo com Koyuncu et al. (1998), que também obtiveram valores de acidez titulável baixos (0,13-0,34 \%).

TABELA 1 - Número de nós do colo da planta até a inserção do primeiro fruto no ramo principal de figueiras. Selvíria - MS, 2007.

\begin{tabular}{cc}
\hline Tratamentos & Médias \\
\hline 'Roxo-de-Valinhos' & $9,00 \mathrm{ab} *$ \\
'Pingo-de-Mel' & $11,5 \mathrm{ab}$ \\
'White Genova' & $14,0 \mathrm{a}$ \\
'White Adriatic' & $13,0 \mathrm{a}$ \\
'Palestino' & $11,5 \mathrm{ab}$ \\
'PI - 440' & $13,5 \mathrm{a}$ \\
'PI - 433' & $7,00 \mathrm{~b}$ \\
'PI - 189' & $12,5 \mathrm{ab}$ \\
'PI - 214' & $12,0 \mathrm{ab}$ \\
'PI - 301' & $14,5 \mathrm{a}$ \\
\hline CV (\%) & 16,97 \\
\hline
\end{tabular}

*Médias nas colunas seguidas de mesma letra não diferem entre si, pelo teste de Tukey, a 5\% de significância. 
TABELA 2 - Médias das características de produção e qualidade dos frutos de figueiras. Selvíria - MS,

\begin{tabular}{|c|c|c|c|c|c|c|c|}
\hline $\begin{array}{c}\text { Tr a t a - } \\
\text { mentos }\end{array}$ & $\begin{array}{c}\mathbf{N}^{0} \text { Frutos/ } \\
\text { planta }\end{array}$ & $\begin{array}{c}\text { Massa/ } \\
\text { fruto }\end{array}$ & $\begin{array}{l}\text { Produ- } \\
\text { tividade }\end{array}$ & $\begin{array}{c}\text { Comprimento } \\
\text { dos } \\
\text { frutos }\end{array}$ & $\begin{array}{c}\text { Diâmetro } \\
\text { dos } \\
\text { frutos }\end{array}$ & $\begin{array}{c}\text { Sólidos } \\
\text { Solúveis }\end{array}$ & $\begin{array}{c}\text { Acidez } \\
\text { Titu- } \\
\text { lável } \\
\end{array}$ \\
\hline & & $\mathrm{g}$ & $\mathrm{t} / \mathrm{ha}$ & $\mathrm{cm}$ & & ${ }^{\circ}$ Brix & $\%$ \\
\hline $\begin{array}{l}\text { Roxo-de- } \\
\text { Valinhos }\end{array}$ & 22,00 bcd* $^{*}$ & $38,56 \mathrm{~b}$ & $2,27 \mathrm{bcd}$ & $5,30 \mathrm{a}$ & $4,17 \mathrm{~b}$ & $12,74 \mathrm{a}$ & $0,15 \mathrm{~b}$ \\
\hline $\begin{array}{l}\text { P i n g o - } \\
\text { de-Mel }\end{array}$ & $28,00 \mathrm{abc}$ & $19,27 \mathrm{~d}$ & $1,38 \mathrm{de}$ & $3,20 \mathrm{~b}$ & $2,90 \mathrm{e}$ & $11,78 \mathrm{ab}$ & $0,18 \mathrm{a}$ \\
\hline $\begin{array}{l}\text { Wh i t e } \\
\text { Genova }\end{array}$ & $14,33 \mathrm{~d}$ & $51,33 \mathrm{a}$ & 1,95 cde & $4,93 \mathrm{a}$ & $4,98 \mathrm{a}$ & $11,51 \mathrm{ab}$ & $0,15 \mathrm{~b}$ \\
\hline $\begin{array}{l}\text { W h i t e } \\
\text { Adriatic }\end{array}$ & - & - & - & - & - & - & - \\
\hline Palestino & $36,00 \mathrm{a}$ & $33,31 \mathrm{bc}$ & $3,23 \mathrm{ab}$ & $4,13 \mathrm{a}$ & $3,67 \mathrm{~cd}$ & $13,68 \mathrm{a}$ & $0,14 \mathrm{~b}$ \\
\hline PI - 440 & $17,00 \mathrm{~d}$ & $21,75 \mathrm{~cd}$ & $0,99 \mathrm{e}$ & $4,43 \mathrm{a}$ & $3,33 \mathrm{de}$ & $9,50 \mathrm{~b}$ & $0,13 \mathrm{~b}$ \\
\hline PI - 433 & $18,67 \mathrm{~cd}$ & $35,67 \mathrm{~b}$ & 1,79 cde & 5,06 a & $4,03 \mathrm{bc}$ & $10,84 \mathrm{ab}$ & $0,13 \mathrm{~b}$ \\
\hline PI - 189 & $30,00 \mathrm{ab}$ & $44,24 \mathrm{ab}$ & 3,76 a & $4,77 \mathrm{a}$ & $4,47 \mathrm{ab}$ & $12,48 \mathrm{ab}$ & $0,14 \mathrm{~b}$ \\
\hline PI - 214 & $20,33 \mathrm{bcd}$ & $43,40 \mathrm{ab}$ & $2,36 \mathrm{bcd}$ & $4,63 \mathrm{a}$ & $4,53 \mathrm{ab}$ & $11,94 \mathrm{ab}$ & $0,13 \mathrm{~b}$ \\
\hline PI - 301 & $23,33 \mathrm{bcd}$ & $43,83 \mathrm{ab}$ & $2,72 a b c$ & $4,70 \mathrm{a}$ & $4,37 \mathrm{ab}$ & $12,41 \mathrm{ab}$ & $0,14 \mathrm{~b}$ \\
\hline $\mathrm{CV}(\%)$ & 16,43 & 10,97 & 16,86 & 15,91 & 4,09 & 9,27 & 7,31 \\
\hline
\end{tabular}

*Médias nas colunas seguidas de mesma letra não diferem entre si, pelo teste de Tukey, a 5\% de significância.

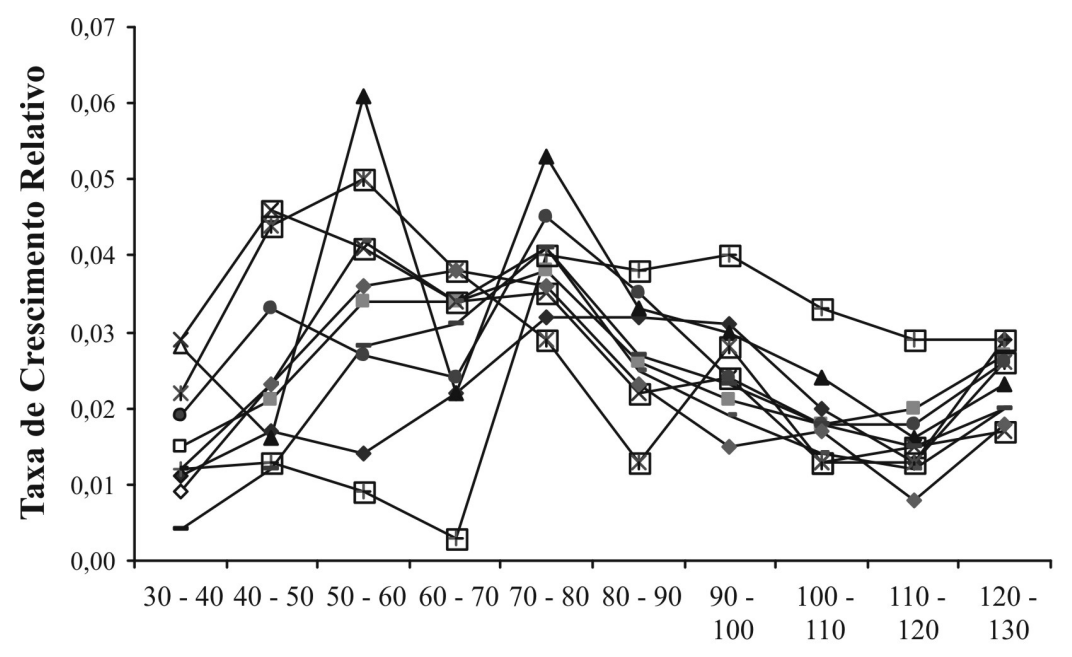

$\prec$ Roxo de _Valinhos'

$\rightarrow-$ 'Pingo de Mel'

$\checkmark-$ 'White Genova'

๑ 'White Adriatic'

娄- 'Palestino'

$\rightarrow$ 'PI - 440'

— 'PI - 433'

- 'PI - 189'

- 'PI - 214'

Número de dias após o plantio

FIGURA 1 - Taxa de Crescimento Relativo (cm/cm.dia) das plantas das cultivares e seleções de figueiras, em diferentes épocas, após o plantio no campo. Selvíria - MS, 2008. 


\section{CONCLUSÕES}

1-Houve variabilidade entre as seleções de plantas irradiadas, assim como destas com as cultivares tradicionais.

2-O tratamento PI-189 foi superior à cultivarpadrão 'Roxo-de-Valinhos' em características de grande importância comercial, como "número de frutos por planta", "massa média por fruto" e "produtividade", igualando-se nas demais características. Assim, mostrando-se com enorme potencial para posteriores estudos, e mesmo em cultivo comercial.

\section{REFERÊNCIAS}

BRASIL - Ministério da Agricultura, Pecuária e Abastecimento. Estatísticas. Disponível em: $<$ http:// www.agricultura.gov.br>. Acesso em: 10 fev. 2005.

CHIARIELLO, N.R.; MOONEY, H.A.; WILLIAMS, K. Growth, carbon allocation and cost of plant tissues. In: PEARCY, R.W.; EHLERINGER, J.R.; MOONEY, H.A.; RUNDEL, P.W. (ed.). Plant physiological ecology: fields and instrumentation. New York: Chapman \& Hall, 1991. p.328-65.

CORREA, L.S.; BOLIANI, A.C. Propagação e instalação da cultura da figueira. In: CORREA, L.S.; BOLIANI, A.C. Cultura da figueira do plantio à comercialização. Ilha Solteira: FAPESP, 1999. p.41-50.

CORREA, L.S.; SANTOS, S.C. Condução e tratos culturais da figueira. In: CORREA, L.S.; BOLIANI, A.C. Cultura da figueira do plantio a comercialização. Ilha Solteira: FAPESP, 1999. p. 51-68.

DOMINGUES, E.T.; TULMANN NETO, A.; TEÓFILO SOBRINHO, J. Importância das mutações somáticas no melhoramento das variedades cítricas. Laranja, Cordeirópolis, v.16, n.2, p.235-249, 1995.

DONINI, B. Breeding methods and applied mutagenesis in fruit plants. In: WORKSHOP EUROPEAN COMMUNITY, 1976, Wageningen. Proceedings... p. $445-478$.
FERRAZ, L. C. C. B. ; PEREIRA, F. M. ; BOLONHEZI, A. C. Danos causados por nematoides de galhas em mudas de figueira cv. Roxo-deValinhos. Revista Brasileira de Fruticultura, Jaboticabal, v.2, n.2, p. 47-53, 1980.

IEA - INSTITUTO DE ECONOMIA AGRÍCOLA. A Cultura do figo em São Paulo. Disponível em: http://www.iea.sp.gov.br/>. Acesso em: abr 2008.

KERKADZE, I.G. Radiation mutagenesis in subtropical crops. Radiatsionnyi Mitagenez-I-EgoRol-V-Evolutsii-I-Selektsii, p.231-254, 1987.

KOYUNCU, M.A. A Study on some fruit characteristics in local fig cultivars grown in Hilvan (URFA, Southern Turkey). Acta Horticulturae, The Hague, n. 480, p. 83-85, 1998.

KUKSOVA,V.B.; PIVEN, N.M.; GLEBA, Y.Y. Somaclonal variation and in vitro mutagenesis in grapevine. Plant Cell Tissue and Organ Culture, Dordrecht v.49, n.1, p.17-27, 1997.

MOREIRA, J. A. A. Efeitos da tensão da água do solo e do parcelamento da adubação nitrogenada, sobre 0 crescimento e a produtividade do feijãovagem (Phaseolus vulgaris- L.). 1993. $100 \mathrm{f}$. Tese (Doutorado) - Faculdade de Ciências Agronômicas, Universidade Estadual Paulista, Botucatu, 1003. .

PENTEADO, S.R. O cultivo da figueira no Brasil e no mundo. In: CORREA, L. de S.; BOLIANI, A.C. Cultura da figueira do plantio à comercialização. Ilha Solteira: FAPESP, 1999. p.1-16.

PEREIRA, F. M. Cultura da figueira. Piracicaba: Livroceres, 1981.73p.

PEREIRA, F.M.; NACHTIGAL, J.C. Botânica, biologia e cultivares de figueira. In: CORREAA, L. de S.; BOLIANI, A.C. Cultura da figueira do plantio à comercialização. Ilha Solteira: FAPESP, 1999. p. 25-36.

PREDIERI, S.; MAGLI, M.; ZIMMERMAN, R.H. Pear mutagenesis in vitro treatment with gammarays and field selection for vegetative form traits. Euphytica, Dordrecht, v.93, n.2, p.227-237, 1997. 
RAIJ, B.V.; CANTARELLA, H.; QUAGGIO J.A.; FURLANI, A.M.C. Recomendações de adubação e calagem para o Estado de São Paulo. Campinas: IAC-FUNDAG, 1997. (Boletim Técnico, 100)

RIBEIRO, I.J. A doenças da figueira. In: CORREA, L. S.; BOLIANI, A.C. Cultura da figueira do plantio à comercialização. Ilha Solteira: FAPESP, 1999. p. 25-36.

SANTOS, P. C.; CORREA, L. S.; TULMANN NETO, A.; BOLIANI, A. C. Sensitividade de estacas de figo a radiação gama. Revista Brasileira de Genética, Ribeirão Preto, v.20, n.3, p.150, 1997.
STONE, L.F.; PORTES, T. de A.; MOREIRA, J.A.A. Efeitos da tensão da água do solo sobre a produtividade e o crescimento do feijoeiro. Pesquisa Agropecuária Brasileira, Brasília, v.23, n.5, p.50310, 1988.

TULMANN NETO, A.; SANTOS, P.C.; LATADO, R.R. Aspectos sobre o Melhoramento da Figueira (Ficus carica L.). In: CORREA, L. de S.; BOLIANI, A.C. Cultura da figueira do plantio à comercialização. Ilha Solteira: FAPESP, 1999. p.165-184.

TURK, R. Effects of harvest time pre colling on fruit quality and cold storage. Ficus carica L, cv. Bursa syahjiu. Acta Horticulturae, The Hague, v.258, p.279-285, 1989. 